as unlocking a chain. Our chains are quite often tangled and complicated. It takes a lot of time and patience. But I say from experience, it is a challenge worth taking.

\section{The journey of creation and the journey of recovery}

The process of making this piece of art was a long and tough journey but I hope others who are currently battling with their own demons will be able to identify with it. I welcome and encourage people to interpret it however they like. For all our journeys are different in their many complexities, but I hope we will all end up at the same destination. Content and healthy.

I must also mention an incredible artist called Shawn Coss, whose interpretations of mental disorders truly touched and inspired me to create this piece. The haunting figures that are scattered around the portrait are features of his work. His talent for expressing such complex emotions encouraged me to express my own, and I hope that others will be inspired to do the same.

\section{About the author}

Lily Aston is a student currently on a gap year. Due to study Psychology at Bristol University in 2022 but currently resides in Eastbourne, UK.

\section{Data availability}

Data availability is not applicable to this article as no new data were created or analysed in its writing.

\section{Funding}

This article received no specific grant from any funding agency, commercial or not-for-profit sectors.

\section{Declaration of interest}

None.

\title{
CULTURAL REFLECTIONS
}

\section{Art and psychiatry in the 21st century: here's to more messy - and magical - entanglements}

\author{
Kai Syng Tan (1)
}

BJPsych Bulletin (2022) 46, 105-108, doi:10.1192/bjb.2021.93

Manchester Metropolitan University, UK

Correspondence to Kai Syng Tan (kai.syng.tan@mmu.ac.uk)

†Commentary on ... A portrait of anorexia nervosa. See this issue.

First received 8 Sep 2021, accepted 8 Sep 2021

(c) The Author(s), 2021. Published by Cambridge University Press on behalf of the Royal College of Psychiatrists. This is an Open Access article, distributed under the terms of the Creative

Commons Attribution licence (https:// creativecommons.org/licenses/by/4.

$0 /$, which permits unrestricted re-use,

distribution, and reproduction in any

medium, provided the original work is properly cited.
Summary In a volatile world, during a time of multiple crises and amid a projected upsurge in mental illnesses as an aftermath of the COVID-19 pandemic, now is a critical time to consider how art and psychiatry can entangle with each other. Submissions like that of Lily Aston can create new spaces for conversation, reflection and constructive collisions. This can help disrupt and extend the state of psychiatry, management of psychiatric services, and education and training in mental healthcare, and advance how we understand other bodies and minds around us, and how knowledge can be created.

Keywords Art and psychiatry; medical humanities; creative health; neurodiversity in the arts; anorexia nervosa.

\section{What can anorexia (actually) look like?}

It has been more than 150 years since 'anorexia nervosa' was first termed. ${ }^{1}$ But what do we know about what anorexia is, and in what ways could art related to anorexia confirm, complicate and/or extend this discussion?

For instance, how will someone with anorexia express what anorexia (actually) feels and looks like in a painting 
(or poem, rap song, film, tango dance, etc.)? What do our observations about artworks say about us? As importantly, what does that which is not depicted and omitted reveal? How does one's subjective lived experience inform the artwork? How does this relate to (their and/or the viewers') learned (mis-)conception of what 'anorexia' should be and that of another person with anorexia or those with other 'non-standard' relationships with food? How does the narrative compare with that created by their healthcare provider and that which is described/prescribed within textbooks, papers and policies? What new insights and indeed new knowledges - including the tacit and embodied - can art that entangles with psychiatry create?

Art - like culture or baldness ${ }^{2}$ - escapes easy definition. But can art help to raise the visibility of mental processes literally and metaphorically - and reveal new insights into them? Can art open up new spaces for the patient and psychiatrist to engage with each other beyond the clinical and/or pharmaceutical? How does this irritate the patient-doctor dynamics and divide? What sort of productive antagonisms can arise when psychiatry engages with artistic practice and research? How can this disrupt dominant narratives around (dis-)order and (ab-)normality? To what extent does artistic quality come into play?

And how can the new culture section in an established platform accessed by researchers and practitioners in psychiatry entangle with some of the above-described tensions, to challenge, and indeed advance, 'the state of psychiatry, management of psychiatric services, and education and training ${ }^{3}$ in mental healthcare?

\section{Fluidity and freedom}

The above are some of the questions that Lily Aston's submission can evoke. Alongside the submitted drawing/painting is a written commentary. The latter provides a level of contextualisation and what Aston has described as 'my own interpretation' of the painting as a 'sufferer' of anorexia nervosa.

So what can we see, and what does Aston say about what we are looking at (or looking for)? The artwork is dominated by a face which is divided diagonally. This illustrates what Aston has described as her 'duality'. One side of her face and paper is in an 'explosion of colours', in paint, to depict 'what lies beneath' (flowers, pills). The other is in black and white, drawn in pencil, to depict an 'absence of self' and 'loss of identity'. Yet, this isn't a hard binary the way Descartes reduces the human body and mind. Instead, like how many understand gender today, the division is 'fluid'. Perhaps like the yin-yang symbol, we are looking at complementary, not contrary forces at play. There are figures in black and white in the side that is colourful, while butterflies - coloured, in black and white, and some both coloured and in black and white - punctuate the entire composition.

Indeed, Aston's work is one of contradictions. While 'surrealistic' (skeletal figures hovering around the skies), it is enthusiastic about realism (meticulous facial make-up and follicular luxuriance). It is not saying much (the subject glances nonchalantly into the distance). At the same time, it seems overtly literal, as if an illustration, a confession or a plea to be heard/seen (the words on the wings of butterflies read 'It's all inside your head', and words on figures in the foreground say 'trapped' and 'I'm sorry').

The commentary also includes Aston's thoughts about the role of art. While the process of making the piece was a 'long and tough journey' for her, what Aston likes most is how art allows her to 'express complicated thoughts and emotions' that 'lie below the surface', which are 'impossible to communicate verbally'. At the same time, she seeks to be non-prescriptive: 'I love how everyone came up with a different approach [to the piece]'. It is the 'completely subjective' nature of art, absence of 'concrete rules, methods or regulations', that opens up a space of 'freedom' for Aston.

\section{Beyond art therapy, inspiration porn and 'public engagement'?}

There are rules and regulations in art - but of course. Like those in psychiatry - and any other facet of human endeavour - these rules and regulations are above and below the surface, written and unwritten. Fortunately, like they are elsewhere too, and especially given the year of reckoning that was 2020 (with the COVID-19 pandemic exposing endemic structural inequalities), these rules and regulations are not stagnant. Instead, they are evolving, questioned and get rewritten, as we learn, unlearn and grow, as individuals and with others, within and across disciplines, communities, societies, cultures, species and so on.

More than 170 years have passed since the BJPsych dropped 'Asylum' from its title. Fewer years have passed since it introduced artworks for its covers. Still, a lot has happened in the practice and discourse around the messy - and magical - entanglements of art and mind.

Tropes such as the 'hysterical female' - unsurprisingly, anorexia nervosa was previously known as 'anorexia hysterica' among other terms ${ }^{1}$ - and 'mad artist' have been popularised, then troubled. Once mocked and ostracised - as reflected in its name - 'outsider' art is now the lingua franca alongside double kisses of arts royalty (Grayson Perry is but one prominent example), institutionalised (with Headway East London, a charity for people with brain injury, shown at London's Barbican, and Project Art Works, a collective of neurodiverse artists, nominated for the 2021 Turner Prize).

Gone were the days when the only kids on the block were 'art therapy' and 'artistic expression by patients' and the often-associated charitable, curative and voyeuristic aspects reminiscent of freak shows of world expos and circuses of the old world (the late Stella Young's Ted Talk on 'inspiration porn' is a good start for the curious on the objectification of alterity ${ }^{4}$ ). Instead, we can now turn to burgeoning discourses and practice in inter- and transdisciplinary fields, especially following the All Party Parliamentary Group on Arts, Health and Wellbeing report proposing 'creative health'. ${ }^{5}$ They include: visual medical humanities ${ }^{6}$ and medical humanities, ${ }^{7}$ disability arts (such as the extensive multidisciplinary artistic practices of The Vacuum Cleaner ${ }^{8}$ and Dolly Sen ${ }^{9}$ ). There is also the blockbuster that is 'arts in health' (led by Daisy Fancourt, as reflected in her extraordinary ascent ${ }^{10}$ ) and critics pointing out its fatal flaws and blind spots (read the review by 
Stephen Clift, Emeritus Professor for the Sidney De Haan Research Centre for Arts and Health ${ }^{11}$ and arts and activism veteran Frances Williams's sharp comparative analysis across Greater Manchester and North Wales ${ }^{12}$ ).

To bring in perspectives that lie beneath, between and behind the surface, new generations of psychiatrists are increasingly emboldened to 'out' their own stories about their mental illnesses and to advocate new, bold ways of doing psychiatry using art (such as in PsychArt ${ }^{13}$ ). Those with hybrid backgrounds are also finding ways to converge ideas across boundaries (such as artist-psychotherapist Patricia Townsend's study ${ }^{14}$ of the creative process through psychoanalysis and psychiatry-trained philosopher Mohammed Abouelleil Rashed on mad activism, antipsychiatry and avant garde cinema ${ }^{15}$ ).

Arguments are being made for the need to use art to make attention-deficit hyperactivity disorder (ADHD) and other processes 'more visible, that is, more seen, more heard, more talked about, not avoided, not dismissed, not spoken about in hushed tones, not just a specialist subject discussed by experts, and not only spoken ill of, because there is always more than one side to any story'. ${ }^{16}$ So too are proposals to foreground quality, 'lofty' art to build cultural intelligence and fuel quality conversations. ${ }^{17}$ Artists are increasingly infiltrating mental health research groups and professional bodies (such as the UK Adult ADHD Network ${ }^{18}$ ). Artists are also using artistic and creative research to engage in critical discourse with psychiatry on the cultural and medical constructs and pursuits of "normativity, ${ }^{19}$ and not just as vehicles of communication or public engagement to make 'serious' research accessible.

Terms have been reclaimed (such as 'sick', for Sick! and Sick of the Fringe festivals). Others have been given new breaths of life, key of which is 'neurodiversity', which will be significant and exciting moving forward. First proposed by Australian sociologist Judy Singer in the 1990 s $^{20}$ the term has, over the years, been contested, protected, discussed, fought over and championed (including by researchers of autism ${ }^{21}$ ). The term is gaining attention as it is increasingly co-opted and objectified by the global elite as a 'next business advantage' and more. ${ }^{22-25}$ Fortunately and as testament to the inclusive nature of the term - yet other counter-narratives are surfacing. These include the alignment of 'neurodiversity' with 'biodiversity'. ${ }^{26,27}$ There are also countless new narratives and new creative research methods (such as 'dyspraxic dysco' and 'neurodivergent leadership') by some 300 researchers and artists worldwide who themselves have 'non-standard' cognitive modes, in the Neurodiversity In/And Creative Research Network (of which Singer and several psychiatrists such as ADHD expert Philip Asherson are also members). ${ }^{28}$ With openly neurodivergent artists increasingly sharing their visions for social change, ${ }^{29,30}$ it is no wonder that those who had studied neurodevelopmental processes as medical deficits are increasingly interested in engaging in the positive aspects. $^{31,32}$ In a recent keynote presentation, a wellrespected leading clinical psychologist in ADHD even coaxed his audience of nearly 900 mental health researchers and professionals to no longer ignore but actively engage in the discourse on neurodiversity. ${ }^{33}$
Cultural and academic institutions - historically conservative and slow-moving - are starting to catch up with some of these developments too. Collections (such as Wellcome and Thackery) are being updated with 'woke', more inclusive and decolonised frameworks, and are foregrounding voices previously deemed to be without agency. Increasingly, there are arts programmes in medical settings (such as in University College London Hospital), arts in health enterprises (such as Aesop) and galleries (such as artist-led Bethlem Gallery, which supports and exhibits artists who are current or former patients of the South London and Maudsley NHS Foundation Trust $^{34}$ ). Universities are training the next generations of 'boundary spanners', through new interdisciplinary arts(mental) health programmes (such as at King's College London, Queen Mary University of London, Birkbeck and St George's University of London; artist Deborah Padfield's health humanities programme at St George's, for instance, was developed from her award-winning doctoral and postdoctoral interventions in the clinical space ${ }^{35}$ ).

\section{Widening the conversation and extending the possibilities}

We are at an exciting juncture of multiplicity, fluidity and new possibilities with regard to culture, art and psychiatry. BJPsych Bulletin's entry into the conversation with a new culture section ${ }^{2}$ is belated. This will be critical, particularly amid a volatile world in a period of multiple crises, and amid a projected upsurge in mental illnesses globally as an aftermath of the COVID-19 pandemic. ${ }^{36,37}$ There aren't any magic bullets - not even art ${ }^{17}$ or psychiatry! - for our challenges, which aren't described as 'wicked' for no reason. Works of art that have continued to intrigue are not those that provide or claim to provide answers, but those that problematise, interrogate and provoke. ${ }^{38}$ Submissions like Aston's can thus open up spaces for reflection, connection and constructive collision to challenge and extend the state of psychiatry, management of psychiatric services, and education and training in mental healthcare. This can advance how we think about and relate to other bodies and minds around us, as well as advance how we understand how knowledge can be created.

\section{About the author}

Kai Syng Tan, PhD, FRSA, SFHEA, is a hyperactive award-winning artist, curator, academic and consultant. She is founder and co-chair of the Global Neurodiversity in/and Creative Research Network.

\section{Data availability}

Data availability is not applicable to this article as no new data were created or analysed in its writing.

\section{Funding}

This research received no specific grant from any funding agency, commercial or not-for-profit sectors. 


\section{Declaration of interest}

None.

\section{References}

1 Gull WWV. Anorexia nervosa (Apepsia Hysterica, Anorexia Hysterica). Obes Res 1997; 5: 498-502.

2 Foreman D. Introducing the new culture section of BJPsych Bulletin. BJPsych Bull 2021; 45: 1-3.

3 Cambridge University Press. Information: BJPsych Bulletin. CUP, 2021 (https://www.cambridge.org/core/journals/bjpsych-bulletin/information [cited 5 Oct 2021]).

4 Young S. I'm not your inspiration, thank you very much. Ted Talks 2014; Apr (https://www.ted.com/talks/stella_young_i_m_not_your_inspiration_ thank_you_very_much [cited 10 Aug 2021]).

5 All Party Parliamentary Group on Arts, Health and Wellbeing. Creative Health: The Arts for Health and Wellbeing - Second Edition (Inquiry Report). APPGAHW, 2017.

6 Johnstone F. Manifesto for a visual medical humanities. Medical Humanities 2018; 31 Aug (https://blogs.bmj.com/medical-humanities/ 2018/07/31/manifesto-for-a-visual-medical-humanities/ [cited 10 Aug 2021]).

7 Callard F, Fitzgerald D. Rethinking Interdisciplinarity across the Social Sciences and Neurosciences. Palgrave Macmillan UK, 2015.

8 French J. James Leadbitter: 'Madlove'. Disability Arts Online 2015; 16 Jan (https://disabilityarts.online/magazine/opinion/james-leadbitter-madlove/ [cited 10 Aug 2021]).

9 Sen D. About me. Dolly Sen 2021 (https://dollysen.com/ [cited 10 Aug 2021]).

10 UCL. Spotlight on Dr Daisy Fancourt. UCL Health of the Public, 2020 (https://www.ucl.ac.uk/health-of-public/response-covid-19/ucl-covid19-research/spotlight-dr-daisy-fancourt [cited 10 Aug 2021]).

11 Clift S. Fancourt, D. and Finn, S. (2019). What is the evidence on the role of the arts in improving health and well-being? A scoping review. Nord J Arts Cult Health 2020; 2: 77-83.

12 Williams F. In a Creative Healthy Place? Situating Arts and Health Within the Discourse of 'the Devolution Revolution' [Doctoral Thesis]. Manchester Metropolitan University, 2019. Available from: https://e-space.mmu.ac. uk/626298/ [cited 10 Aug 2021]

13 PsychART. Who are we? PsychART, 2021 (https://www.psychart.org. uk/index.php [cited 10 Aug 2021]).

14 Townsend P. Creative States of Mind: Psychoanalysis and the Artist's Process. Routledge, 2019

15 Rashed MA. Madness and the Demand for Recognition: A Philosophical Inquiry into Identity and Mental Health Activism. Oxford University Press, 2019.

16 Tan KS. What else could 'neurodiversity' look like? Disability Arts Online, 2018; 19 Feb (http://disabilityarts.online/magazine/opinion/elseneurodiversity-look-like/ [cited 22 Feb 2018]).

17 Tan KS, Asherson P. How 'lofty' art can help the medical world reimagine mental health. The Conversation, 2018; 31 Oct (http://theconversation.com/how-lofty-art-can-help-the-medical-world-reimagine-mentalhealth-105689 [cited 31 Oct 2018]).

18 UK Adult ADHD Network. Cultural \& creative consultancy. UKAAN, 2021 (https://www.ukaan.org/cultural-creative-consultancy.htm [cited 10 Aug 2021])

19 Tan KS, Asherson P. Come Sit on a mat with an artist and a psychiatrist to have a chat about mind wandering, gingerbread men, shark baits, and the interface of normal/abnormal behaviour. Mind the Gap Blog, 2017; 12 May (https://mind-the-gap.live/2017/05/12/come-sit-on-a-mat-withan-artist-and-a-psychiatrist-to-have-a-chat-about-mind-wanderinggingerbread-men-shark-baits-and-the-interface-of-normalabnormalbehaviour/ [cited 22 May 2017]).

20 Singer J. NeuroDiversity: The Birth of an Idea (2nd edn). Judy Singer, 2016.

21 Happé F. Autism: cognitive deficit or cognitive style? Trends Cogn Sci 1999; 3: 216-22.

22 Austin RD, Pisano GP. Neurodiversity as a competitive advantage. Harvard Business Review Magazine 2017; May-Jun (https://hbr.org/2017/05/neuro diversity-as-a-competitive-advantage [cited 19 Aug 2020]).

23 Nesta. Nine emerging trends in the management and support of innovation. Nesta, 2019; 25 Feb (https://www.nesta.org.uk/blog/nine-emerging-trendsin-the-management-and-support-of-innovation/ [cited 31 Aug 2020]).

24 Orduña N. The next talent opportunity for the digital workplace? Neurodiversity. World Economic Forum 2019; 12 Aug (https://www. weforum.org/agenda/2019/08/neurodiversity-workplace-opportunity/ [cited 13 Aug 2019]).

25 Silberman S. NeuroTribes: The Legacy of Autism and How to Think Smarter About People Who Think Differently. Allen \& Unwin, 2015.

26 Singer J. What is neurodiversity? Reflections on Neurodiversity, 2020 (https://neurodiversity2.blogspot.com/p/what.html [cited 10 Aug 2021])

27 Baron-Cohen S. Editorial Perspective: Neurodiversity - a revolutionary concept for autism and psychiatry. J Child Psychol Psychiatry 2017; 58 744-7.

28 Tan KS, Dhital R. Neurodiversity. JISCMail, 2020 (https://www.jiscmail. ac.uk/cgi-bin/webadmin?AO=NEURODIVERSITY [cited 20 Mar 2020]).

29 Mistry A. DNR_RND: reimagining the arts sector post-pandemic. Disability Arts Online, 2021 (https://disabilityarts.online/collections/dnr_rnd-re imagining-the-arts-sector-post-pandemic/ [cited 20 Jul 2021]).

30 Tan KS. Novel viruses require artful solutions. Royal Society of the Arts 2020; 26 May (https://www.thersa.org/discover/publications-andarticles/rsa-comment/2020/05/novel-viruses-require-artful-solutions [cited 25 Jul 2020]).

31 Lesch K-P. 'Shine bright like a diamond!': is research on high-functioning ADHD at last entering the mainstream? J Child Psychol Psychiatry 2018; 59: 191-2.

32 Sedgwick JA, Merwood A, Asherson P. The positive aspects of attention deficit hyperactivity disorder: a qualitative investigation of successful adults with ADHD. Atten Defic Hyperact Disord 2019; 11: 241-53.

33 Faraone SV. New perspectives on research and clinical care for attention deficit hyperactivity disorder. 14th International Conference on ADHD (Berlin, 29 May 2021) (https://seera.events/adhd/files/userfiles/files/ Faraone.pdf [cited 10 Aug 2021]).

34 Bethlem Gallery. About Bethlem Gallery. Bethlem Gallery, 2021 (https:// bethlemgallery.com/who-we-are/ [cited 10 Aug 2021]).

35 St George's University of London. Dr Deborah Padfield. St George's University of London, 2021 (https://www.sgul.ac.uk/profiles/deborahpadfield [cited 10 Aug 2021]).

36 Rajkumar RP. COVID-19 and mental health: a review of the existing literature. Asian J Psychiatry 2020; 52: 102066.

37 Torales J, O'Higgins M, Castaldelli-Maia JM, Ventriglio A. The outbreak of COVID-19 coronavirus and its impact on global mental health. Int Soc Psychiatry 2020; 66: 317-20.

38 Tan KS. An exploration of running as metaphor, methodology, material through the RUN! RUN! RUN! Biennale \#r3fest 2016. Sport Soc 2019; 22: $829-45$.

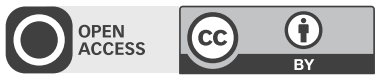

